\title{
Nasopharyngeal Cancer pNX TNM Finding v6 and v7
}

National Cancer Institute

\section{Source}

National Cancer Institute. Nasopharyngeal Cancer pNX TNM Finding v6 and v7. NCI

Thesaurus. Code C64473.

Nasopharyngeal cancer in which the regional lymph nodes cannot be assessed. (from AJCC 6th and 7th Eds.) 